\title{
Application of Bradford's Law on Publication Analysis of Plagiarism: A Scientometric Profile
}

\author{
Chandran Velmurugan ${ }^{1 *}$, Natarajan Radhakrishnan ${ }^{2}$ \\ ${ }^{1}$ Research Scholar, Department of Library and Information Science, Periyar University, Salem- 636011 , \\ Tamilnadu, INDIA \\ ${ }^{2}$ Associate Professor, Department of Library and Information Science, Periyar University, Salem- 636011 , \\ Tamilnadu, INDIA \\ *Corresponding Contact: \\ Email: murugan73@gmail.com
}

\begin{abstract}
An attempt has been made to analyze the scholarly publications of Plagiarism as reflected through web of science in global wise. The study covers in different variables such as sources, year wise, top 10 authors, and top 25 institutions, top 25 country wise, top 20 journals and top 25 keyword wise distribution of contributions. The Time span is for the year between 2010 and 2014 which is limited only recent five years only. The findings of the study reveal that the majority of $442(55.8 \%)$ scientific publications have been published in scholarly journals. The maximum number of articles were published in 2013 and the lowest number i.e. 130 (16.4\%) of research papers were published in 2010. The TLCS and TGCS are increased in the year 2010 and gradually it has been decreased in the year 2014. It is noticed that the share of publications output by Indian authors is 16 articles i.e. $2.07 \%$ of 776 papers published by authors from all over the world in different journals of 5 years.
\end{abstract}

Keywords: Plagiarism, bibliometrics, scientometrics, research publications, WoS, Bradford's law, CPP, TLCS, TGCS, scientific publications, scholarly communications

$4 / 29 / 2017$

Source of Support: Nil, No Conflict of Interest: Declared

This article is is licensed under a Creative Commons Attribution-NonCommercial 4.0 International License.

Attribution-NonCommercial (CC BY-NC) license lets others remix, tweak, and build upon work non-commercially, and

although the new works must also acknowledge \& be non-commercial.

\section{INTRODUCTION}

Plagiarism is one of the contemporary debate and serious issue among the scholastic community such as students, faculty members and research scientists. According to the Oxford English Dictionary (2011), plagiarism defines as taking the work of another as "literary theft." The verb to "plagiarize" is defined as "To take and use as one's own (the thoughts, writings, or inventions of another person);" and "to copy (literary work or ideas) improperly or without acknowledgement; (occas.) to pass off as one's own the thoughts or work of (another)". OED definition, in the strict sense recycling papers would not be plagiarism and Merriam-Webster Dictionary (2011) defines as "plagiarize" is to steal and pass off (the ideas or words of another) as one's own: use (another's production) without crediting the source and to commit literary theft: present as new and original an idea or 
product derived from an existing source. Scientific misconduct is a growing concern, not only among researchers and science policy makers but also among society as a whole (Garci'a-Romero and Estrada-Lorenzo, 2014). Plagiarism is as "the substantial reproduction of another study that bringing to no novelty to the scientific community without proper acknowledgement" (Errami and Garner, 2008). This present study has been made an attempt to evaluate the research articles of plagiarism in Universal level in terms of document and year wise author wise, institution wise, country wise, journal wise and keyword wise distribution of contributions during the selected period of recent five years.

\section{RELATED WORK}

A huge number of scientometric study as well as bibliometric study have carried out in terms of different subjects such as biology, biotechnology, life science, R\& D literature outputs, doctoral studies by eminent research scientists. We here, some of the current review of literature have taken. To support and strengthen the current research, authors' early works have chosen and the works dealt with in terms of authorship pattern, collaborative research work in Library Herald (Velmurugan and Radhakrishnan, 2015), Journal of Intellectual Property Rights (Velmurugan, 2014, 2015), Indian Journal of Pure and Applied Physics (Velmurugan, 2014), Annals of Library and Information Studies (Velmurugan, 2013), in DESIDOC Journal of Library and Information Technology (Velmurugan and Radhakrishnan, 2015), publication research trends in Webology (Velmurugan, 2015), in IETE Technical Review Journal (Velmurugan and Radhakrishnan, 2014), in Journal of Intellectual Property Rights (Velmurugan, 2014), Indian Journal of Pure and Applied Physics (Velmurugan, 2014), Indian Journal of Biotechnology (Velmurugan and Radhakrishnan, 2014), research productivity of Amylase in Microbiology in Indian Perspective (Velmurugan and Radhakrishnan, 2015), Literature output of Plagiarism (Velmurugan and Radhakrishnan, 2015), in Journal of Information Literacy (Velmurugan, and Radhakrishnan, 2015) and quantitative analysis of scientific publications Output on Engineering Journal (Velmurugan and Radhakrishnan, 2015), Literature output of Supply Chain Management (Velmurugan and Radhakrishnan, 2015).

\section{OBjectives}

The main purpose of this study is to examine the scientific literature research trends on Plagiarism in global level during the period 2010 - 2014 and the other objectives are as follows:

- To ascertain the year-wise distribution of the publications;

- To identify source wise distribution;

- To study the top 10 authors of research publications;

- To examine top 15 country wise distribution;

- To observe the top 20 journal wise distribution

- To find out top 25 institutions and

- To trace the top 25 keyword wise distribution

\section{Methodology}

Plagiarism related scientific publications retrieved through WOS by searching for the string "Plagiarism". The analysis is based on the research articles published by various scientists throughout the world. The Time span was set to between 2010 and 2014 which is limited only recent five years only. Twelve document types were found among the total 
756 scholarly publications contributed in the website. Generally, the most frequent document type was peer viewed scholarly journal articles (442), which involved 55.8 per cent and the TLCS was 375 and TGCS was 1371 of the total publications. The data has transferred to MS Excel spreadsheet for further statistical analysis to evaluate the appropriate estimation of research data.

\section{ANALYSIS AND RESULTS}

\section{Source types and Languages}

It is inferred from the analysis, the highest number of documents was peer viewed scholarly journal articles (442), which involved 55.8 per cent and the TLCS was 375 and TGCS was 1371 of the total publications. The other sources such as editorial materials (188; 23.7 per cent), letter (78; 9.8 per cent), book review $(37 ; 4.7$ per cent ), review $(15 ; 1.9$ per cent), news item $(12 ; 1.6$ per cent), correction $(8 ; 0.1$ per cent), meeting abstract $(7 ; 0.9$ per cent), proceedings $(2 ; 0.3$ per cent), biographical item $(1 ; 0.1$ per cent $)$, poetry $(1 ; 0.1$ per cent) and book chapter $(1 ; 0.1$ per cent). While, the original peer reviewed articles were still noteworthy and focuses the scientometric analysis, but we count other items such as the proceedings papers, editorial materials, letter, book review, review, news item, correction, meeting abstract, proceedings, biographical item and poetry and book chapter.

In terms of language wise distribution of literature outputs, English was the foremost and dominant language counting for 732 (92.4 per cent) research articles. Other least number of publications languages such as Spanish (15), French (14), German (12), Turkish (four), Portuguese (three), Dutch (two), Korean (two), Lithuanian (two), Catalan (one), Hungarian (one), Italian (one), Polish (one), Slovak (one), Slovene (one).

Table 1: Source wise distribution

\begin{tabular}{|l|c|c|}
\hline Document Type & Publications & Rank (share of total publications) \\
\hline Article & 442 & $1(55.8)$ \\
\hline Editorial Material & 188 & $2(23.7)$ \\
\hline Letter & 78 & $3(9.8)$ \\
\hline Book Review & 37 & $4(4.7)$ \\
\hline Review & 15 & $5(1.9)$ \\
\hline News Item & 12 & $6(1.6)$ \\
\hline Correction & 8 & $7(1.0)$ \\
\hline Meeting Abstract & 7 & $8(0.9)$ \\
\hline Proceedings Paper & 2 & $9(0.3)$ \\
\hline Biographical-Item & 1 & $10(0.1)$ \\
\hline Poetry & 1 & $11(0.1)$ \\
\hline Book Chapter & 1 & $12(0.1)$ \\
\hline Total & 792 & 100.0 \\
\hline
\end{tabular}

\section{Growth rate of publication and citation scores}

Table 2 shows the chronology wise distribution of literature output which have been published and indexed in WOS database during the year 2010 to 2014. Out of 792, the most highest number i.e. $182(23.0 \%)$ of articles were published in 2013, followed by 181 (22.8\%) research papers were produced in 2012 and the lowest number i.e. $130(16.4 \%)$ of research papers were published in 2010. Total global citations are increased in the year 2010 and slowly it has been decreased in the year 2014. It is noted that there is a fluctuation trend during the period. 
Table 2: Year wise growth rate of research articles

\begin{tabular}{|c|c|c|c|c|c|}
\hline Year & Recs & Percent & TLCS & TGCS & CPP \\
\hline 2010 & 130 & 16.4 & 201 & 1162 & 8.94 \\
\hline 2011 & 151 & 19.1 & 138 & 588 & 3.89 \\
\hline 2012 & 181 & 22.8 & 148 & 504 & 2.78 \\
\hline 2013 & 182 & 23.0 & 47 & 235 & 1.29 \\
\hline 2014 & 148 & 18.7 & 22 & 77 & 0.52 \\
\hline Total & 792 & 100.0 & 556 & 2566 & 3.24 \\
\hline
\end{tabular}

\section{Most productive country wise papers}

Table 3 identifies the global wise distribution of literature output cited in WOS and top 10 institutions were taken to measure statistically, out of 68 countries, 200 (25.3\%) research articles have been published by USA with TLCS is 191 and TGCS is 639 and the Internationally collaborative publications were 124 which has got the first rank, followed by Unknown countries $192(24.2 \%)$ scholarly papers were published with TCLS is 104 and TGCS is 259 and also measured the ICP i.e. 47 has occupied in the second position is the next to USA, followed by UK, Australia and Canada respectively and India has got the 9th position during the period.

Table 3: Top 10 most productive countries / territories during 201-2014

\begin{tabular}{|c|c|c|c|c|c|c|c|c|}
\hline Country / territory & TLCS & TGCS & $\mathrm{TP}$ & TP R \% & SP & $\mathrm{SP} / \mathrm{TP} \%$ & ICP & $\mathrm{CP} / \mathrm{TP} \%$ \\
\hline USA & 191 & 639 & 200 & $1(25.3)$ & 76 & 38.00 & 124 & 62.00 \\
\hline Unknown & 104 & 259 & 192 & $2(24.2)$ & 145 & 75.53 & 47 & 24.47 \\
\hline UK & 56 & 970 & 70 & $3(8.8)$ & 26 & 37.14 & 44 & 62.86 \\
\hline Australia & 25 & 711 & 44 & $4(5.6)$ & 17 & 38.64 & 27 & 61.36 \\
\hline Canada & 39 & 133 & 33 & $5(4.2)$ & 17 & 51.52 & 16 & 48.48 \\
\hline Peoples R China & 28 & 58 & 32 & $6(4.0)$ & 13 & 40.62 & 19 & 59.37 \\
\hline Germany & 11 & 84 & 23 & $7(2.9)$ & 5 & 21.73 & 18 & 78.27 \\
\hline Spain & 4 & 75 & 21 & $8(2.7)$ & 5 & 23.81 & 16 & 76.19 \\
\hline India & 4 & 11 & 16 & $9(2.0)$ & 12 & 75.0 & 4 & 25.0 \\
\hline Croatia & 37 & 80 & 15 & $10(1.9)$ & 6 & 40.0 & 9 & 60.0 \\
\hline
\end{tabular}

\section{Ranking of Institutions in Plagiarism research during 2010-2014}

It is evident from the Table 4 represents that the institution based literature outputs which were collected from the web of science for the period 2010-2014. The results mirrored that most of the research articles were published unknown $(=128,16.2 \%)$ with 102 total global citations and placed in the first rank and followed by University of Hong Kong $(=11,1.4 \%)$ with 18 citations and has ranked in the second place and in the third place has occupied by Hainan Med University, Joseph Ayobabalola University, University of Warwick and Yale University $(=7,0.9 \%)$ with different citations respectively. 
Table 4: Ranking of Institutions

\begin{tabular}{|l|l|c|c|c|c|}
\hline$\#$ & Institution & Recs & Percent & TLCS & TGCS \\
\hline 1 & Unknown & 128 & 16.2 & 69 & 102 \\
\hline 2 & University of Hong Kong & 11 & 1.4 & 7 & 18 \\
\hline 3 & Hainan Med University & 7 & 0.9 & 3 & 3 \\
\hline 4 & Joseph Ayobabalola University & 7 & 0.9 & 0 & 0 \\
\hline 5 & University of Warwick & 7 & 0.9 & 1 & 18 \\
\hline 6 & Yale University & 7 & 0.9 & 3 & 27 \\
\hline 7 & Columbia University & 6 & 0.8 & 2 & 3 \\
\hline 8 & Harvard University & 6 & 0.8 & 22 & 39 \\
\hline 9 & Indiana University & 6 & 0.8 & 3 & 14 \\
\hline 10 & Ohio State University & 6 & 0.8 & 3 & 11 \\
\hline 11 & University of Queensland & 6 & 0.8 & 7 & 23 \\
\hline 12 & Athabasca University & 5 & 0.6 & 1 & 3 \\
\hline 13 & Charles Sturt University & 5 & 0.6 & 8 & 15 \\
\hline 14 & Rijeka University & 5 & 0.6 & 17 & 26 \\
\hline 15 & University of British Columbia & 5 & 0.6 & 12 & 59 \\
\hline
\end{tabular}

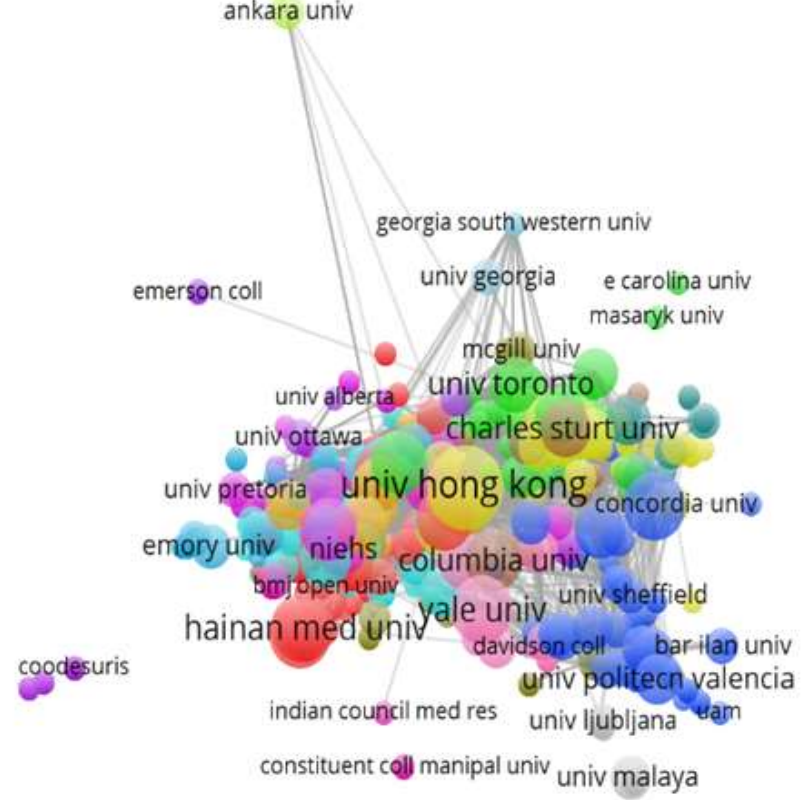

Map 1: Network based Label view of Institution

\section{World Research output and share of Indian literature}

Table 5 indicates the world outputs and Indian sharing research papers during the period of study and noticed that there is a constant growth of literature output in Plagiarism 
research in the world. It is identified at the same time that the share of publications output by Indian authors is 16 articles i.e. $2.07 \%$ of 776 papers published by authors from all over the world in different source journals of five years.

Table 5: Research output (share of Indian authors)

\begin{tabular}{|l|c|c|c|}
\hline Year & Recs in World & Recs in India & India's Share \% \\
\hline 2010 & 129 & 1 & 0.78 \\
\hline 2011 & 148 & 3 & 2.02 \\
\hline 2012 & 178 & 3 & 1.68 \\
\hline 2013 & 181 & 1 & 0.55 \\
\hline 2014 & 140 & 8 & 5.71 \\
\hline Total & 776 & 16 & 2.07 \\
\hline
\end{tabular}

\section{Research Productivity (Individual Authors Performance)}

The author performance in the analysis of the present study focused on research productivity of most prolific individual authors (Top 15) contribution of distributions and also covered the different parameters of citations scores such as TLCS, TLCS/t, TLCSx, TGCS, TGCS/t, and TLCR. Among the 795 literature outputs only 3 articles were unknown as results of the remaining 792 research papers were produced by 1320 authors. It is identified from the below table 5 noticed that the TLCS (Total Local Citation Score), TGCS (Total Global Citation Score), TLCR (Total Local Citation References), TLCSb (Total Global Citation Score in the beginning), TLCSe (Total Local Citation Score at the end). In this context, Wiwanitkit $\mathrm{V}$ had got the first position and his total numbers of research publications are 20 and he has got 6 in TLCS, 12 in TGCS, 24 in TLCR and followed by unnamed authors are in the second position, Joob B, Bilic-Zulle L, Brennan PA respectively.

Table 6: Research Productivity of Individual Authors

\begin{tabular}{|c|l|c|c|c|c|c|c|c|c|}
\hline$\#$ & \multicolumn{1}{|c|}{ Author } & Recs & Percent & TLCS & TLCS/t & TLCSx & TGCS & TGCS/t & TLCR \\
\hline 1 & Wiwanitkit V & 20 & 2.5 & 6 & 2.00 & 0 & 12 & 4.58 & 24 \\
\hline 2 & Anonymous & 11 & 1.4 & 7 & 1.40 & 7 & 0 & 0.00 & 0 \\
\hline 3 & Joob B & 7 & 0.9 & 2 & 0.75 & 0 & 4 & 1.42 & 11 \\
\hline 4 & Bilic-Zulle L & 6 & 0.8 & 23 & 6.40 & 17 & 32 & 9.07 & 21 \\
\hline 5 & Brennan PA & 5 & 0.6 & 1 & 0.50 & 1 & 1 & 0.50 & 0 \\
\hline 6 & Chaddah P & 5 & 0.6 & 2 & 1.25 & 0 & 7 & 5.50 & 2 \\
\hline 7 & Coats AJS & 5 & 0.6 & 4 & 0.85 & 1 & 788 & 170.18 & 3 \\
\hline 8 & Hupp JR & 5 & 0.6 & 1 & 0.50 & 1 & 1 & 0.50 & 0 \\
\hline 9 & Li YY & 5 & 0.6 & 7 & 2.67 & 2 & 15 & 5.33 & 14 \\
\hline 10 & Lingen MW & 5 & 0.6 & 1 & 0.50 & 1 & 1 & 0.50 & 0 \\
\hline 11 & Samman N & 5 & 0.6 & 1 & 0.50 & 1 & 1 & 0.50 & 0 \\
\hline 12 & Wiltfang J & 5 & 0.6 & 1 & 0.50 & 1 & 1 & 0.50 & 0 \\
\hline 13 & Zhang YH & 5 & 0.6 & 10 & 5.83 & 2 & 16 & 8.83 & 19 \\
\hline 14 & Cosma G & 4 & 0.5 & 1 & 0.25 & 0 & 9 & 3.37 & 6 \\
\hline 15 & Jia XY & 4 & 0.5 & 9 & 4.83 & 1 & 14 & 6.83 & 11 \\
\hline
\end{tabular}

TLCS-Total Local Citation Score, TGCS -Total Global Citation Score, TLCR -

Total Local Citation References, TLCSb - Total Global Citation Score in the beginning, TLCSe - Total Local Citation Score at the end. 


\section{Identification of Journal wise distributions in Plagiarism output}

It is evident from the Table 7 depicts the significant journal publication in plagiarism scientific research papers. Out of 485 journals, "CURRENT SCIENCE" has bring out the highest number of articles $13(1.6 \%)$ with TGCS (Total Global Citation Score) is 5 and TLCR (Total Local Citation References) is also 5, and it dominates in the first rank of research output followed by "BIOCHEMIA MEDICA, ETHICS \& BEHAVIOR and SCIENCE AND ENGINEERING ETHICS" have 12 (each 1.5\%) and they have got in the second position and "JOURNAL OF ENGLISH FOR ACADEMIC PURPOSES, JOURNAL OF SECOND LANGUAGE WRITING and NATURE" have each $11(1.4 \%)$ and they have occupied in the third position of the publication output.

Table 7: Journal wise distributions in Plagiarism output

\begin{tabular}{|l|l|c|c|c|c|}
\hline Sl.no & Journals & TR & TP & TC & ACPP \\
\hline 1 & Current Science & 13 & 1.6 & 10 & 0.78 \\
\hline 2 & Biochemia Medica & 12 & 1.5 & 47 & 3.92 \\
\hline 3 & Ethics \& Behavior & 12 & 1.5 & 11 & 0.92 \\
\hline 4 & Science and Engineering Ethics & 12 & 1.5 & 35 & 2.92 \\
\hline 5 & Journal of English For Academic Purposes & 11 & 1.4 & 19 & 1.72 \\
\hline 6 & Journal of Second Language Writing & 11 & 1.4 & 48 & 4.36 \\
\hline 7 & Nature & 11 & 1.4 & 37 & 3.36 \\
\hline 8 & Anesthesia And Analgesia & 9 & 1.1 & 11 & 1.22 \\
\hline 9 & Annals of Internal Medicine & 8 & 1.0 & 35 & 4.38 \\
\hline 10 & Croatian Medical Journal & 8 & 1.0 & 27 & 3.38 \\
\hline 11 & Assessment \& Evaluation in Higher Education & 7 & 0.9 & 24 & 3.43 \\
\hline 12 & Journal of Medical Ethics & 7 & 0.9 & 94 & 13.43 \\
\hline 13 & Learned Publishing & 7 & 0.9 & 28 & 4 \\
\hline 14 & American Journal of Roentgenology & 6 & 0.8 & 10 & 1.67 \\
\hline 15 & $\begin{array}{l}\text { Anadolu Kardiyoloji Dergisi-The Anatolian Journal of } \\
\text { Cardiology }\end{array}$ & 6 & 0.8 & 6 & 1 \\
\hline 16 & Computers \& Education & 6 & 0.8 & 31 & 5.17 \\
\hline 17 & Current Medical Research and Opinion & 6 & 0.8 & 24 & 4 \\
\hline 18 & Higher Education Research \& Development & 6 & 0.8 & 3 & 0.5 \\
\hline 19 & Studies in Higher Education & 6 & 0.8 & 39 & 6.5 \\
\hline 20 & $\begin{array}{l}\text { Accountability in Research-Policies and Quality } \\
\text { Assurance }\end{array}$ & 5 & 0.6 & 7 & 1.4 \\
\hline TR- Total records, TP- Total percentage, TC- Total citations, & & & \\
ACPP-Average citation per paper & & & \\
\hline
\end{tabular}

\section{Bradford's Law of Scattering}

In the year 1934, Samuel Clement Bradford introduced the Bradford's law of scattering to test the publications. The Bradford's law is to elucidate that a group of journals could be arranged in an order of decreasing productivity and revealed that journals which yield the most productive articles are coming first and the most unproductive in the last. In keeping with this law, the journals are to be grouped into a number of zones each producing a similar number of articles. On the other hand, the number of journals in each zone will be increasing speedily. Then the relationship between the zones is $1: n: n 2$. For describing the scattering phenomena, the following formula has been adopted by the researchers. The formula is $F(X)=a+b \log x$, Where $F(X)$ - is the cumulative number of references as 
contained in the first- $x$ most productive journal and ' $a$ ' and ' $b$ ' are constants. Researchers have counted the total number of journals for this present study is 485 .

Table 8: Bradford's law of scattering

\begin{tabular}{|c|c|c|c|c|c|c|c|c|}
\hline Rank & NJ & CJ & NP & TP & CP & Log N & \%age of CP & \%age of CJ \\
\hline 1 & 1 & 1 & 13 & 13 & 13 & 0 & 1.64 & 0.21 \\
\hline 2 & 3 & 4 & 12 & 36 & 49 & 1.386 & 6.19 & 0.82 \\
\hline 3 & 3 & 7 & 11 & 33 & 82 & 1.946 & 10.35 & 1.44 \\
\hline 4 & 1 & 8 & 9 & 9 & 91 & 2.079 & 11.49 & 1.65 \\
\hline 5 & 2 & 10 & 8 & 16 & 107 & 2.303 & 13.51 & 2.06 \\
\hline 6 & 3 & 13 & 7 & 21 & 128 & 2.565 & 16.16 & 2.68 \\
\hline 7 & 6 & 19 & 6 & 36 & 164 & 2.944 & 20.71 & 3.92 \\
\hline 8 & 8 & 27 & 5 & 40 & 204 & 3.296 & 25.76 & 5.57 \\
\hline 9 & 8 & 35 & 4 & 32 & 236 & 3.555 & 29.79 & 7.22 \\
\hline 10 & 27 & 62 & 3 & 81 & 317 & 4.127 & 40.03 & 12.78 \\
\hline 11 & 52 & 113 & 2 & 104 & 421 & 4.727 & 53.16 & 23.30 \\
\hline 12 & 371 & 485 & 1 & 371 & 792 & 6.184 & 100 & 100 \\
\hline
\end{tabular}

\section{Log value of cumulative journals}

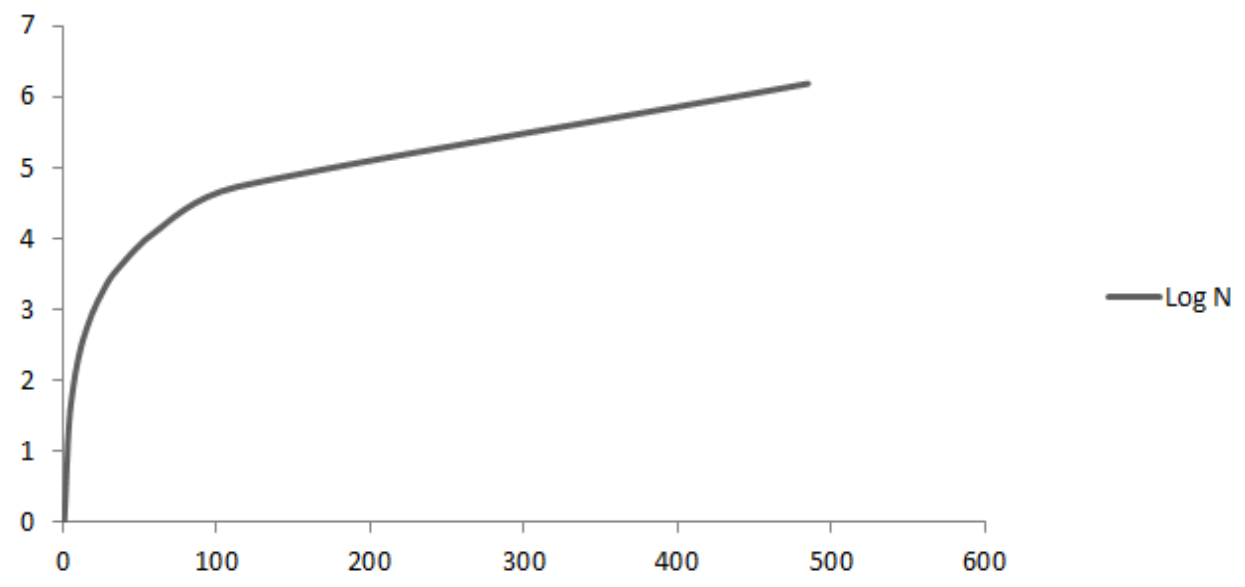

Figure 1: Log value of cumulative scientific journals

Table 9: Zone wise distribution

\begin{tabular}{|c|c|c|c|c|c|}
\hline Zone & Journals & Journal \% & Articles & Article $\%$ & Multiplier \\
\hline 1 & 19 & 3.92 & 164 & 20.71 & - \\
\hline 2 & 95 & 19.59 & 257 & 32.45 & 5.0 \\
\hline 3 & 371 & 76.49 & 371 & 46.84 & 3.91 \\
\hline Total & 485 & 100 & 792 & 100 & $4.455(\mathrm{mv})^{*}$ \\
\hline
\end{tabular}

${ }^{*}$ Mean value 


\section{Zone wise distribution}

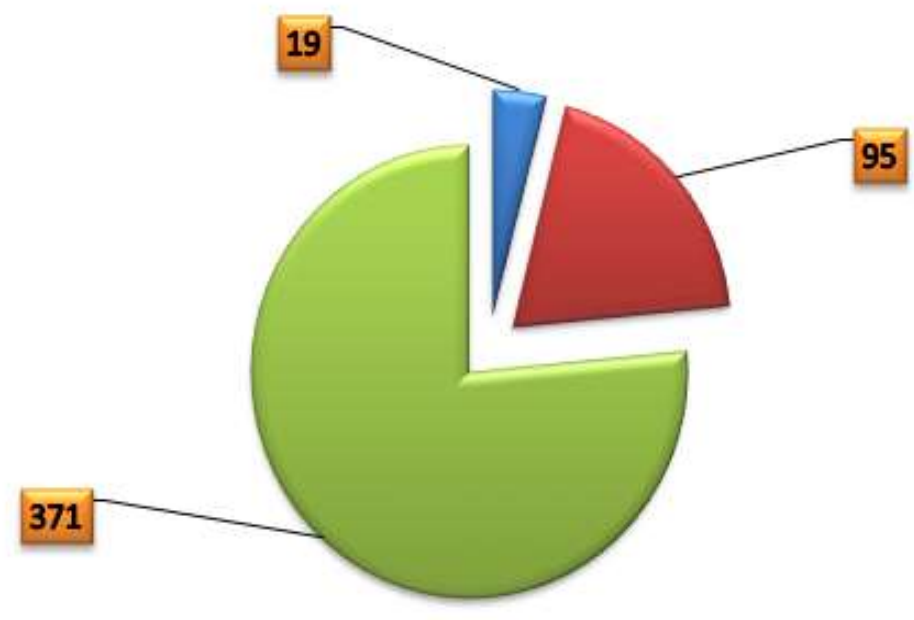

Q

밀one 2

$\square$ Zone 3

Figure 2: Zone wise distribution

Table 9 and Figure 2 indicates that the distribution of scholarly journals and contribution of articles have classified into three zones. According to Bradford, the zones, indicated will form an approximately geometric series in the form 1: n: n2. But, it is identified that the relationship of each zone in the present study is 19:95:371. The ratio depicts that it does not fit into the Bradford's law of distribution. The results reveal that the distributions of core journals were published by a few numbers of journals. It finds here from the analysis, 63 refer to the number of journals in the Nucleus and the mean Bradford multiplier is 3.975.

Table 10: Top 15 Cited References in Plagiarism output

\begin{tabular}{|c|l|c|c|c|c|}
\hline$\#$ & Author & Year & Journal name & Total Records & Percent \\
\hline 1 & Park C & 2003 & Assess Eval High Education & 45 & 5.7 \\
\hline 2 & Pennycook A & 1996 & Tesol Quart & 36 & 4.5 \\
\hline 3 & Martinson BC & 2005 & Nature & 31 & 3.9 \\
\hline 4 & McCabe DL & 2001 & Ethics Behav & 31 & 3.9 \\
\hline 5 & Pecorari D & 2003 & J Second Lang Writ & 31 & 3.9 \\
\hline 6 & Fanelli D & 2009 & Plos One & 30 & 3.8 \\
\hline 7 & Howard RM, & 1995 & Coll Engl & 30 & 3.8 \\
\hline 8 & Ashworth P & 1997 & Stud High Education & 28 & 3.5 \\
\hline 9 & McCabe DL & 1997 & Res High Education & 23 & 2.9 \\
\hline 10 & Roig M & 1997 & Psychol Rec & 23 & 2.9 \\
\hline 11 & Roig M & 2001 & Ethics Behav & 23 & 2.9 \\
\hline 12 & Scanlon PM & 2002 & J Coll Student Dev & 23 & 2.9 \\
\hline 13 & Errami M & 2008 & Nature & 21 & 2.7 \\
\hline 14 & Shi L & 2004 & Writ Commun & 20 & 2.5 \\
\hline 15 & Angelil-Carter S & 2000 & Stolen Language Plag & 19 & 2.4 \\
\hline
\end{tabular}

\section{FINDINGS}

We can conclude that Plagiarism scientific publications research in the world has revealed the impact of understanding the plagiarism for the development. However, the study 
started in recent decades, there is an optimistic growth in the research globally. The study evaluates that the highest number of contributions were published in the year 2013. The majority of the articles have been contributed by multiple authors. Plagiarism has to be avoided writing theses not only theses but also writing any type of academic document. In such a way, Indian authors have produced very least articles of plagiarism compare with foreign authors. It is observed from the study that plagiarism awareness is needed for Indian academic community such as researchers, scientists, and LIS Professionals so as to improve the quality of education.

\section{REFERENCES}

Errami, M., \& Garner, H. R. (2008). A tale of two citations. Nature, 451, 397-399.

García-Romero, A \& Estrada-Lorenzo J M. (2014). A bibliometric analysis of plagiarism and selfplagiarism through De'ja`vu, Scientometrics, 101, 381-396.

Merriam-Webster Dictionary (2011), New Dictionary Words for 2011, https://www.merriamwebster.com/

Oxford English Dictionary (2011), March 2011 update, http:/ / www.oed.com/

Plagiarism, n. (2011). OED Online (3rd. Ed.). Retrieved from: http://www.oed.com, accessed on $24^{\text {th }}$ November 2015.

Plagiarize. (2011). Merriam-Webster Dictionary. Retrieved from: http://www.merriam-webster.com, accessed on $24^{\text {th }}$ November 2015.

Velmurugan, C (2014). Research Output with Special Reference to Authorship Pattern and Collaborative Research Work of the Journal of Intellectual Property Rights (JIPR) During 20072012, Journal of Information Technology and Library Science, 2 (1), 1-8 (ISSN 2347 - 9760).

Velmurugan, C and Radhakrishnan, N. (2015). Authorship Trends and Collaborative research work on Library Herald: a Scientometric Analysis, Information Science and Digital Libraries edited by Somvir, S, International Research Publication House, Delhi, ISBN: 978-93-84443-09-2, pp 173-186.

Velmurugan, C and Radhakrishnan, N. (2015). Literature output of Plagiarism: a Scientometric approach through Web of Science, Combating Plagiarism: a new role for Librarian edited by Manaswini Patra and Sudhir Kumar Jena, S.K. Book Agency, New Delhi, ISBN: 978-93-8315-8560, pp 78-88.

Velmurugan, C and Radhakrishnan, N. (2015). Research Productivity of Amylase in Microbiology in Indian Perspective: a Scientometric analysis, Microbial Production of Amylase in Bacillus Cereus Sp, Edited by Manimaran, D, Velmurugan, C and Elangovan, N, Dr, LAMBERT Academic Publishing (LAP), Germany, 128-143. ISBN: 9783659771071.

Velmurugan, C. \& Radhakrishnan, N. (2015). A Scientometric Analysis of Research Papers Published on Pharmacognosy as reflected in the Web of Science. Advances in Pharmacognosy and Phytomedicine, 1(1), 27-40.

Velmurugan, C. \& Radhakrishnan, N. (2015). Scholarly Communications DESIDOC Journal of Library \& Information Technology (DJLIT): a Scientometric approach International Journal of Library and Information Studies, 5 (3), 14-20.

Velmurugan, C. \& Radhakrishnan, N. (2015). Scientometric observations of Authorship Trends and Collaborative Research on DESIDOC Journal of Library and Information Technology, Collnet Journal of Scientometrics and Information Management, 9:2, 193-204, DOI: 10.1080/09737766.2015.1069957.

Velmurugan, C. \& Radhakrishnan, N. (2015). Webology journal: a scientometric profile. International Journal of Information Dissemination and Technology (IJIDT), 5(2), 137-142. 
Velmurugan, C. (2013). Bibliometric analysis with special reference to Authorship Pattern and Collaborative Research Output of Annals of Library and Information Studies for the Year 2007 2012. International Journal of Digital Library Services, 3 (3), 2013, 13-21.

Velmurugan, C. (2014). Access Pattern of Online Journals among Library Users in Engineering College Central Libraries, Chennai, Tamilnadu, India: A Comparative Study, International Journal of Digital Library Services, 2014, 14-34.

Velmurugan, C. (2014). Authorship Pattern and Collaborative Research Output of Indian Journal of Pure and Applied Physics (IJPAP), International Journal of Art \& Humanity Science (IJAHS), 1 (2), (Sep-Oct), 37-41, e-ISSN: 2349-5235.

Velmurugan, C. (2014). Research Trends in Indian Journal of Pure and Applied Physics (IJPAP) for the Year 2009 - 2012, Asian Review of Social Sciences, 3 (1), 2014, 24-28(ISSN: 2249 - 6319).

Velmurugan, C. (2014). Research Trends in Journal of Intellectual Property Rights (JIPR): A Bibliometric Study, Library Philosophy and Practice (e-journal), Paper 1043. http://digitalcommons.unl.edu/libphilprac/1043

Velmurugan, C. and Radhakrishnan, N. (2014). Publication Research Trends on Technical Review Journal: A Scientometric Study, International Journal of Digital Library Services (IJDLS), 45-55.

Velmurugan, C. and Radhakrishnan, N. (2014). Research Analysis by means of Scientometric Techniques on Biotechnology, International Journal of Multidisciplinary Consortium (IJMC), 2 (1), 256-266.

Velmurugan, C. and Radhakrishnan, N. (2015). Collaborative Research and Authorship Pattern of Intellectual Property Rights, Journal of Information Management, 2(2), 77-87.

Velmurugan, C. and Radhakrishnan, N. (2015). Journal of Information Literacy: A Scientometric Profile, Journal of Information Sciences and Application, 3 (1), 1-9.

Velmurugan, C. and Radhakrishnan, N. (2015). Literature output of Supply Chain Management: A Scientometric approach, Journal of Organizational Behaviour, 3(2), 31-44.

Velmurugan, C. and Radhakrishnan, N. (2015). Quantitative Analysis of Scientific Publications Output on Engineering Journal: A Scientometric Study, Journal of Information Sciences and Application, 3 (1), 19-30. 
